\title{
Erratum to: Surgical risk model for acute diffuse peritonitis based on a Japanese nationwide database: an initial report on the surgical and 30-day mortality
}

Tohru Nakagoe $\cdot$ Hiroaki Miyata $\cdot$ Mitsukazu Gotoh $\cdot$ Takayuki Anazawa

Hideo Baba $\cdot$ Wataru Kimura $\cdot$ Naohiro Tomita $\cdot$ Mitsuo Shimada

Yuko Kitagawa $\cdot$ Kenichi Sugihara $\cdot$ Masaki Mori

Published online: 17 January 2015

(C) Springer Japan 2015

\section{Erratum to: Surg Today}

DOI 10.1007/s00595-014-1026-x

In Tables 3 and 5, there were errors in the platelet counts.

In both tables, the following corrections should be made:

$<15,000 / \mu \mathrm{L}$ should be $<150,000 / \mu \mathrm{L}$

$<12,000 / \mu \mathrm{L}$ should be $<120,000 / \mu \mathrm{L}$

$<8,000 / \mu \mathrm{L}$ should be $<80,000 / \mu \mathrm{L}$

The online version of the original article can be found under doi:10.1007/s00595-014-1026-x.

T. Nakagoe $\cdot$ H. Miyata $\cdot$ M. Gotoh $\cdot$ H. Baba $\cdot$ W. Kimura .

N. Tomita $\cdot$ M. Shimada $\cdot$ Y. Kitagawa

The Japanese Society of Gastroenterological Surgery,

Database Committee, Tokyo, Japan

H. Miyata $\cdot$ M. Gotoh

National Clinical Database (NCD), Tokyo, Japan

M. Gotoh $(\bowtie) \cdot$ T. Anazawa

Department of Regenerative Surgery, Fukushima Medical

University, 1 Hikarigaoka, Fukushima 960-1295, Japan

e-mail: mgotoh@fmu.ac.jp

K. Sugihara $\cdot$ M. Mori

The Japanese Society of Gastroenterological Surgery,

Tokyo, Japan 